\title{
Particle Pollution Inside and Outside of Tohid Hospital In Sanandaj and Modeling of Dispersion Using Surfer Software
}

\author{
Ameneh Yousefzadeh ${ }^{1}$, Saeed Dehestani Athar ${ }^{2}$, Ebrahim Darvishi ${ }^{3}$, Manouchehr Ahmadi Hedayati ${ }^{4}$, \\ Rasoul Nassiri Kalmarzi ${ }^{5}$, Afshin Maleki ${ }^{6}$ \\ 1. Msc of Student Environmental Health Engineering, Student Research Committee, 005AKurdistan University of Medical \\ Sciences, Sanandaj, Iran. ORCID: 0000-0002-2637-5746 \\ 2. Assistant Professor, Environmental Health Research Center, Research Institute for Health Development, Kurdistan \\ University of Medical Sciences, Sanandaj, Iran. ORCID: 0000-0002-8236-3598 \\ 3. Assistant Professor, Environmental Health Research Center, Research Institute for Health Development, Kurdistan \\ University of Medical Sciences, Sanandaj, Iran. ORCID: 0000-0002-7857-1781 \\ 4. Assistant Professor, Department of Microbiology, Faculty of Medicine, Kurdistan University of Medical Sciences, \\ Sanandaj, Iran, ORCID: 0000-0003-0654-8918 \\ 5. Associate Professor, Department of Internal Medicine, Faculty of Medicine, Kurdistan University of Medical Sciences, \\ Sanandaj, Iran. ORCID: 0000-0001-6351-2909 \\ 6. Professor, Environmental Health Research Center, Research Institute for Health Development, Kurdistan University of \\ Medical Sciences, Sanandaj, Iran. Tel: 0876625132, Email: maleki43@yahoo.com, ORCID: 0000-0001-8261-8717
}

\begin{abstract}
Background and Aim: People spent most of their time indoors. Therfore, quality of indoor air ,especially in the therapeutic settings is of particular importance. This study aimed to determine the level of pollutants in indoor and outdoor air of Tohid Hospital in Sanandaj.

Materials and Methods: In this cross-sectional descriptive study 120 indoor and outdoor air samples were collected by TES-5200 copper counterpart machine made by TES company in Taiwan. Particulate matter samples were collected from 9 wards and also 3 stations in every ward in the hospital. Also air samples were obtained from 3 selected stations outside the hospital. Samples were taken from the selected sites twice. The results were analyzed by Excel and SPSS software.

Results: According to the results of this study, the highest and lowest concentrations of particulate matter $\left(\mathrm{PM}_{2.5}, \mathrm{PM}_{4}, \mathrm{PM}_{7}, \mathrm{PM}_{10}\right)$ belonged to the emergency room and the operating room, respectively. The highest level of $\mathrm{PM}_{1}$ concentration was detected in the ICU ward. There was no significant relationship between temperature and particle concentration and also between moisture and particle concentration in the wards of the hospital. In regard to particulate matter, the emergency department was the most contaminated ward and the operating room had the best condition.
\end{abstract}

Conclusion: The relationship between the concentrations of particles in the outdoor and indoor air indicated the penetration of these particles from outside into the hospital building. Also, outdoor air can affect indoor air quality.

Keywords: Hospital, Particulate matter, Air quality, Air pollution

Received: Mar 23, 2020

Accepted: Dec 7, 2020

How to cite the article: Ameneh Yousefzadeh, Saeed Dehestani Athar, Ebrahim Darvishi, Manouchehr Ahmadi Hedayati, Rasoul Nassiri Kalmarzi, Afshin Maleki. Survey of airborne contamination inside and outside of Tohid hospital in Sanandaj in terms of suspended particles and modeling of dispersion by Surfer software. SJKU 2021;26(6):11-23.

Copyright (C) 2018 the Author (s). Published by Kurdistan University of Medical Sciences. This is an open access article distributed under the terms of the Creative Commons Attribution-Non Commercial License 4.0 (CCBYNC), where it is permissible to download, share, remix, transform, and buildup the work provided it is properly cited. The work cannot be used commercially without permission from the journal 


\section{بررسى آلودتى هواى داخل و خارج بيمارستان توحيد شهر سندج از نظر ذرات معلق و مدلسازى يراكندكى آن توسط نرمافزار}

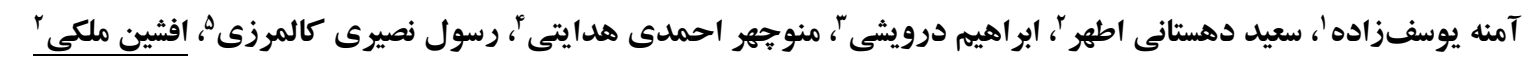

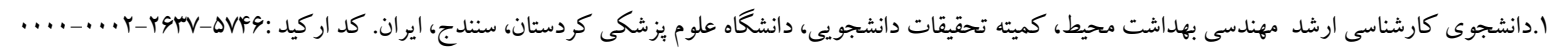

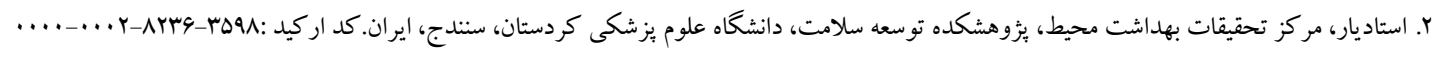

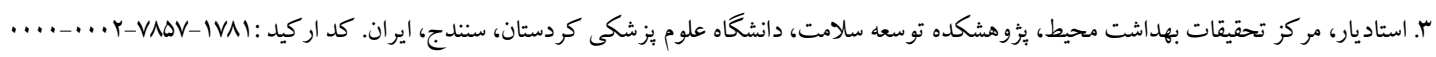

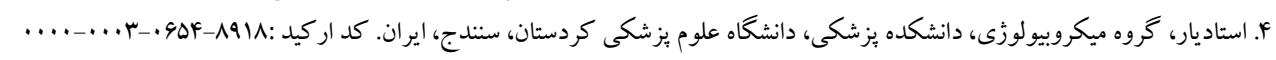

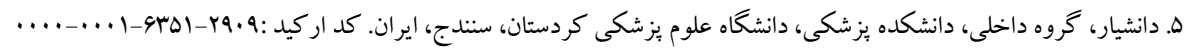

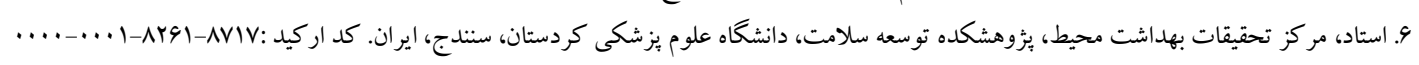

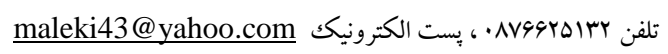

جكيده

زمينه و هدف: با توجه به اينكه بخش اعظم زمان مردم در داخل ساختمان سرى مىشود، كيفيت هواى داخل ساختمان خصوصاً در محيطهاى درمانى از اهميت ويزهاى برخوردار است. مطالعه حاضر با هدف تعيين ميزان آلايندهاى ذرات معلق در هواى

$$
\text { داخل و خارج بيمارستان توحيد شهر سنندج انجام گرديد. }
$$

مواد و روش حها: اين مطالعه مقطعى و از نوع توصيفى است. با استفاده از دستگاه يارتيكل مس كانتر TES-5200 ساخت شر كت TES تايوان تعداد · rا نمونه از هواى داخل و خارج بيمارستان جمع آورى شدند. نمونهاى ذرات معلق 9 بخش و از هر بخش ب ايستخاه به منظور نمونه بردارى از هواى داخل بيمارستان و ب ايستًاه جهت نمونه بردارى از هواى بيرون بيمارستان انتخاب شدند. نمونه بردارى با دو بار تكرار انجام شد. نتايج حاصل با استفاده از نرم افزارهاى Excel و SPSS تجزيه و تحليل كرديد. يافته ها: طبق نتايج اين مطالعه، بيشترين و كمترين غلظت ذرات $)$ (PM و اتاق عمل مشاهده گرديد. بيشترين ميزان آلودگى از نظر غلظت ذرات PMI مربوط به بخش ICU بود. مطابق آناليزهاى انجام كرفته، بين دما و غلطت ذرات و همجِنين رطوبت و غلظت ذرات، براى همهى بخشهاى مورد مطالعه ارتباط معنىدارى مشاهده نشد. در اين مطالعه از نظر ميزان ذرات، آلودهترين بخش اورزانس بوده و بهترين شرايط براى بخش اتاق عمل مشاهده شده است. نتيجه Fيرى: رابطه بين ميزان ذرات در هواى آزاد و هواى داخل بيمارستان نشان دهنده نفوذ اين ذرات از محيط بيرون به داخل ساختمان است. هواى بيرون مىتواند كيفيت هواى داخل ساختمان راهم تحت تأثير قرار دهد. كلمات كليلى : بيمارستان، ذرات معلق، كيفيت هوا، آلودكى هوا

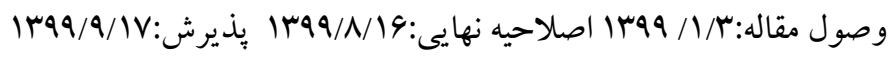


از بين رفتن ظرفيت ريه و صدمه به ريهها است كه در نتيجهـ

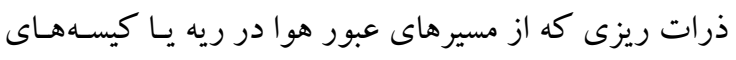

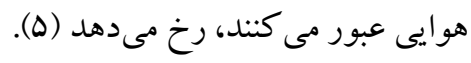

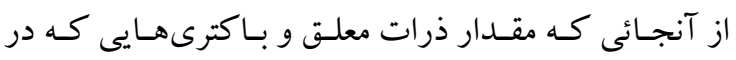

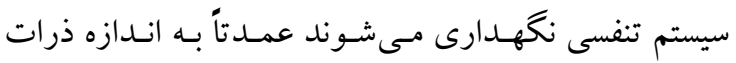

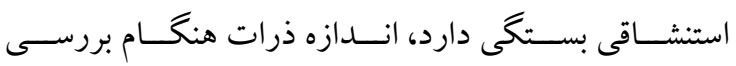
ميكروار كانيسمهاى هوا و ارتباط آنها با عفونت هاى تنفسى دارد

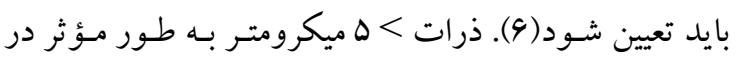

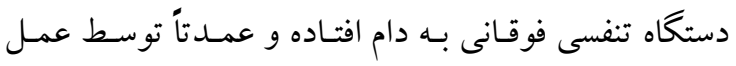

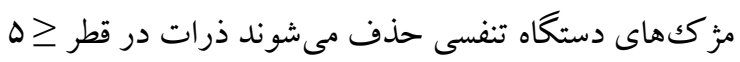

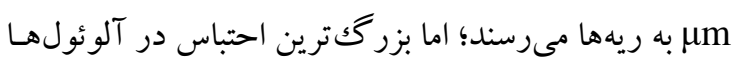
از قطر ا تا ب ميكرومتر است (V).

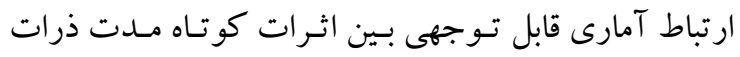

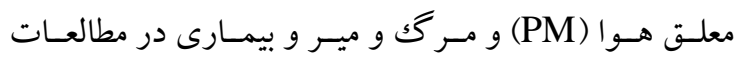
جند گانه متعدد گزارش شده است. مطالعات متعدد نيز نشان

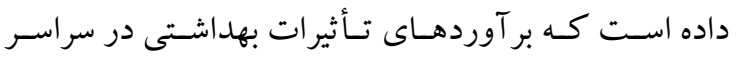
جوامع و فصول مختلف متفاوت است (^). در دهه گذشـته،

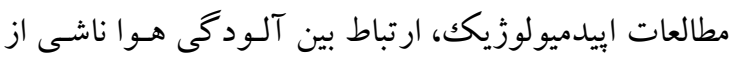
ذرات معلق (PM) و افزايش ميزان بذيرش بيمارستان بـراى بيمارىهاى تنفسى و قلب و عـروق را در مطالعـات سراسر جهان ثبت كردهاند (9). در مطالعهاى كه وانگك و همكاران

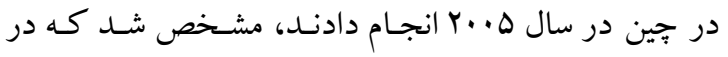
تابستان، غلظت ذرات معلق PM 2.5 وPM10 در هـواى

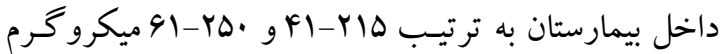
بر متر مكعب است. همجنـين، غلظت ايـن ذرات معلق در

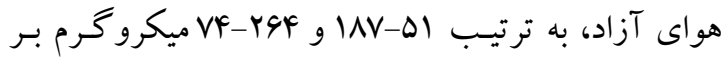

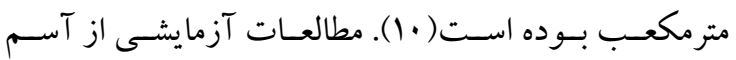

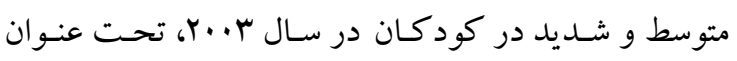

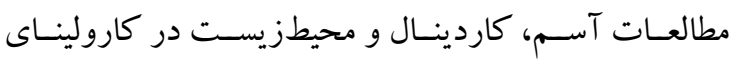

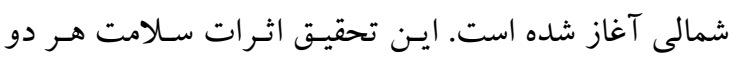

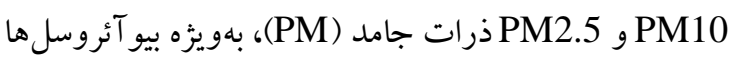
را در ارزيابى اثرات مواجهه بلندمدت شخصى بـا كودكـان

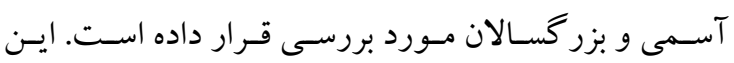

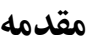
ذرات معلق هو ا اصطلاحى اسـت كه بـراى توصيف ذرات

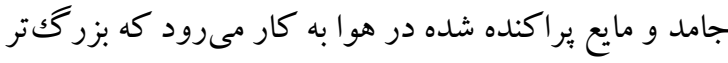

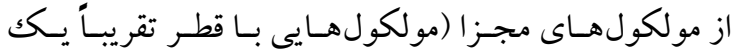

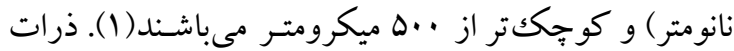

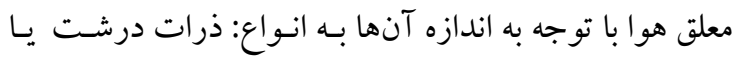

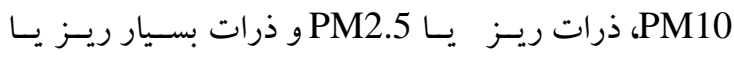

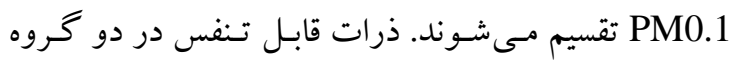

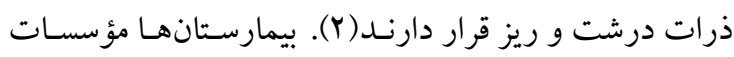

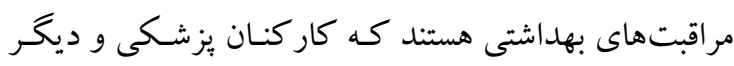

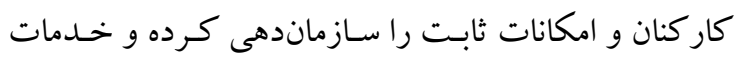

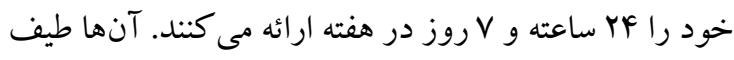

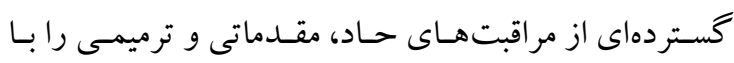

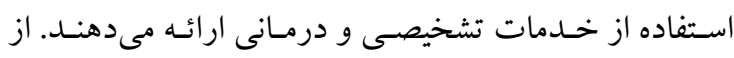
آنجايى كه ذرات معلق، حاملان عوامل بيولوزيكى از جمله ونه

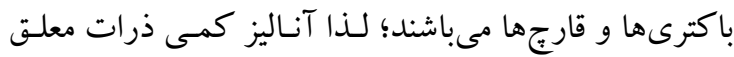
و ارتباط آن بـا (PM1,PM2.5, PM4, PM7, PM10)

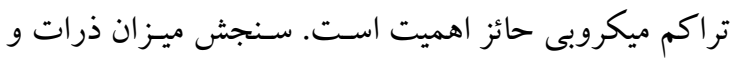
همجِنين بيو آئروسل ها به عنو ان شاخص مناسـبى جهـت بيـان كيفيت هواى داخل در مقايسه با هواى خـارج بيمارستان در

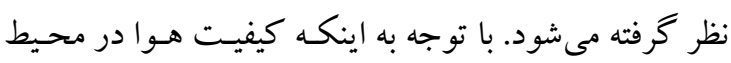

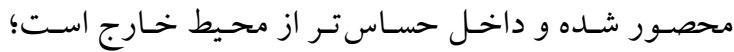
بنابر اين مديريت و كنترل كيفيت هوا در داخل محيطهـاى محصور حياتى است (Y). ذرات موجود در محيط محصسور

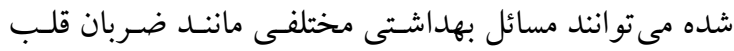
نامنظم، آسم تشديد شده، كـاهش عملكرد ريـه و حمـلات قلبى خفيف را ايجاد كنند. از جمله اثرات حساد بهداشتى در غلظتهاى بالاى ذرات ريز، افزايش شـدت مـرك و مير، افزايش شيوع آسم و برونشيت و افزايش ميزان عفونتهـاى سيستم تنفسى است(F). اين ذرات علاوه بـر اينكـه بـه طـور

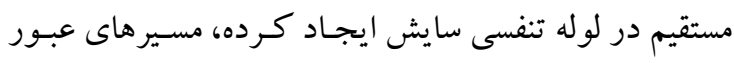

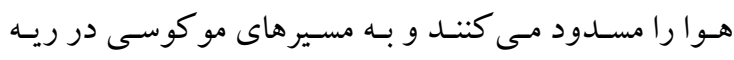

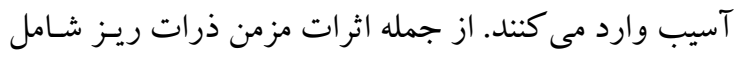


شد و در خارج از بيمارستان هـم ب ايستَّاه در نظر گرفتـه

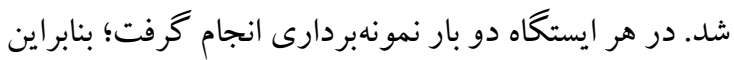
در حالت كلى تعداد •و نمونه mass و .9 نمونه در حالت count از ايستخاههاى مختلف جمع آورى شد (Y) (I ).

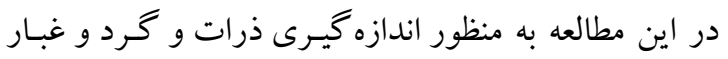
هواى بخش هاى مختلف بيمارستان، از دستخاه غبـار سـنج

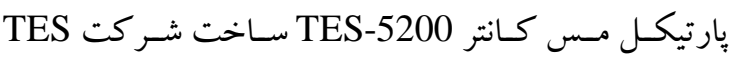
تايوان استفاده شد. اين دستخاه قابليت اندازه گيرى ذرات در دو حالت (count mode) جهت سنجش تعـداد ذرات در سايزهاى

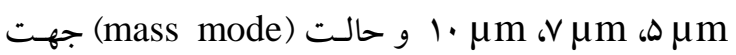
اندازهيرى سطح تراكم حجمى (غلظت ذرات) مطابق بـا و استانداردهاى PM1, PM2.5, PM4, PM7, PM10 را دارا است. دستگاه همزمان با ايـن مـوارد، حجـم يـا

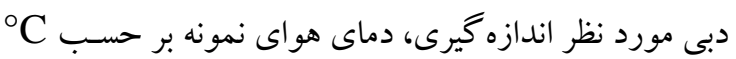

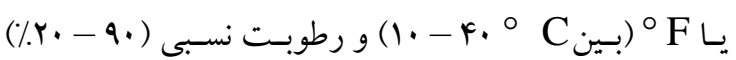

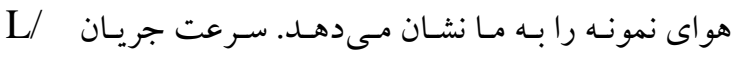

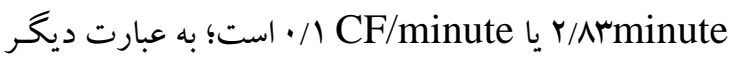
مدت زمان نمونهبردارى يكك دقيقه است. محل نمونهبردارى

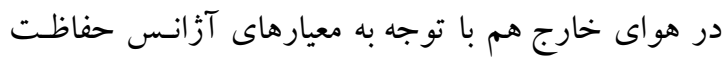
محيطزيست آمريكا، بـيش از · r متـر فاصله از خيابـان،

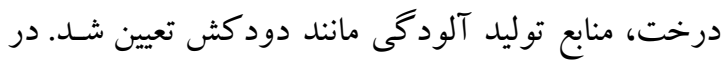

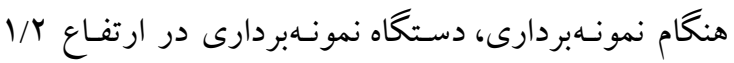
مترى از سطح زمين و با فاصله بيش از يكك متر از ديوارها

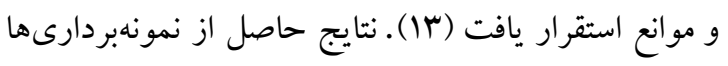

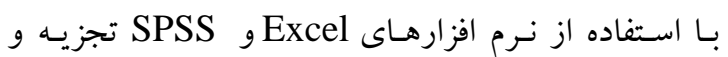

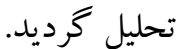

يافتهها

Ir. در اين ثُوهش از بيمارستان توحيد شهر سـنـدج تعـداد

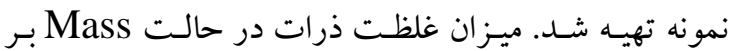

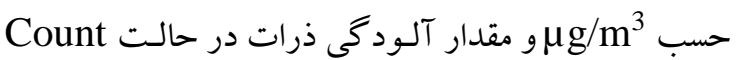
بر بايه سايز ذرات، بر حسب particle/m محاسبه شد.
بيو آئروسـل هـاى هـو ابرد مـى توانـــد واكسنش هـاى حسـاس،

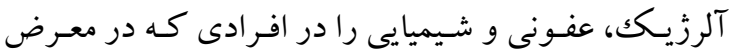
خطر هستـند، ايجـاد نماينـد. نمونـهــاى محيطى PM2.5 و

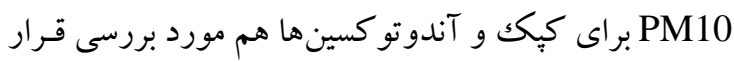

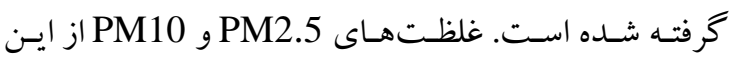
بيو آئروسل ها به عنوان عملكرد توده PM و حجم نمونههاى

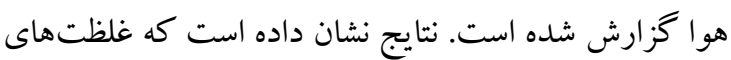

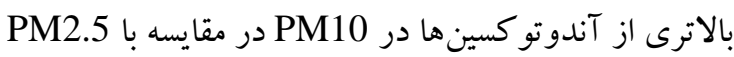

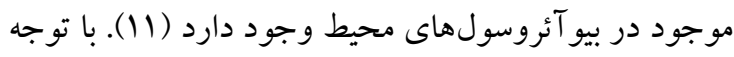

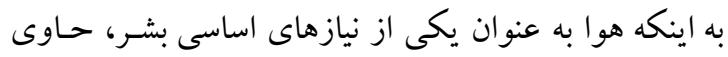
ذرات و ميكروار گانيسمهاى مختلفى اســ؛ للذا بـه دنبـال تنفس در محيطهاى با آلودگى هاى بـالا، استنشـاق مقـدار

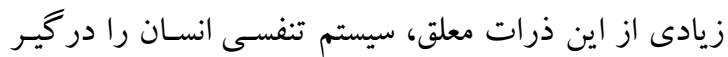
مى سازد. با توجه بـه نبـود مطالعـات در زمينه تعيـين ميزان لـان آلايندههاى هو ابرد در بيمارستانهاى استان كردسـتان، ايـن

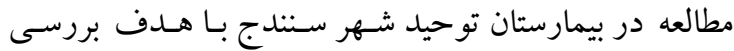
آلود گى ذرات معلق هواى داخل و خارج بيمارستان توحيد

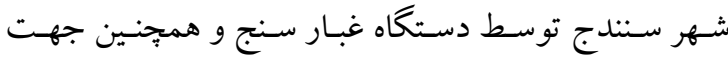
صحت بيشتر نتايج به دست آمده، مدلسازى براكندگى اين

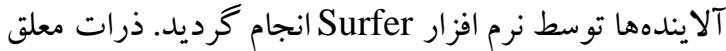
در هواى بخشهاى مختلف بيمارستان بـر حسب انـدازه و غلظت مورد بررسى قرار گرفت.

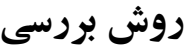

اين مطالعه كه يكك مطالعه توصيفى و از نوع مقطعى بـود در آن ميزان ذرات موجود در هو ایى داخل بخش هاى مختلف و همجينين هواى خارج بيمارستان توحيـد شهر سـنتدج مـورد

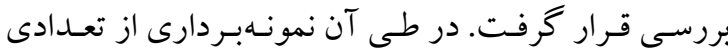
بخشهاى داخل بيمارستان (داخلى مردان، داخلى زنان، ريه،

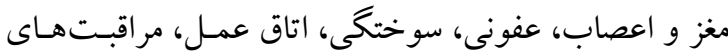
ويزه، اورزانس) و همجنين هواى بيرون بيمارستان به منظور

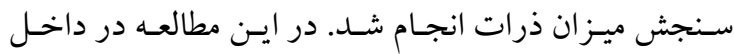
بيمارستان 9 بخش و در هر بخش سه ايستخاه در نظر گرفتـه 
نتايج نشان داد كـه تعـداد ذرات مشـاهده شـده بـه تفكيكك

غلظتها (PM) بين بخشها متفاوت است.(جدول ()

PM1， بررسى كيفيت هواى بيمارستان از نظر غلظت ذرات PM2.5, PM4, PM7, PM10 در حالت كلى ميانكين دماى بخشها PF/VV

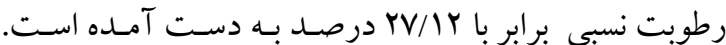

جدول 1. ذرات مشاهده شده به تفكيك بخشهاى مورد مطالعه ( $\left(\mu \mathrm{g} / \mathrm{J}^{3}\right)$

\begin{tabular}{|c|c|c|c|c|c|c|c|}
\hline TSP & PM10 & PM7 & PM4 & PM2.5 & PM1 & ميانكين و انحر اف معيار & بخش \\
\hline 1N/99 & D ט & $1 \cdot / 1$ & $9 / 10$ & $1 / 99$ & $\cdot / \mu$ & ميانگين & \multirow{2}{*}{ داخلى مردان } \\
\hline$\Delta / F \Delta$ & $r / \cdot 1$ & $1 / 9 r$ & $1 / 19$ & $\cdot / \kappa$ & $\cdot / 11$ & انحر اف معيار & \\
\hline 1N/99 & D טז/rו & $1 \cdot / \wedge 9$ & $\Delta / ৭ \Delta$ & r & . & ميانگين & \multirow{2}{*}{ داخلى زنان } \\
\hline$\Delta / F \Delta$ & $r / \cdot 1$ & Y/৭9 & $r / \cdot V$ & $\cdot / \Lambda \Delta$ & $\cdot / r$ & انحراف معيار & \\
\hline rN/IT & YN/NT & $r Y / F A$ & 1.1 .9 & $r / F$ & . & ميانگين & \multirow[b]{2}{*}{ ريه } \\
\hline $19 / 19$ & $I Y / T V$ & 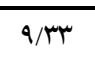 & 每 & $.19 \mathrm{~V}$ & $\cdot / r$ & انحر اف معيار & \\
\hline $11 / \mathrm{M}$ & $1 / \cdot 9$ & $\Delta / 9 \Lambda$ & $r / .9$ & .194 &.$/ \pi$ & ميانگين & \multirow{2}{*}{ مغز و اعصاب } \\
\hline$Y / \cdot V$ & $1 / 99$ & $1 / 90$ & $1 / 1 \pi$ & $\cdot / r r$ &.$/ 1$ & انحر اف معيار & \\
\hline 9 & F/VQ & $F / \Delta q$ & $r / 9$ & $\cdot 191$ & 每 & ميانگين & \multirow{2}{*}{ سوختكى } \\
\hline$\cdot / \Delta r$ &.$/ 49$ & $\cdot / 0$ & $\cdot / \Lambda$ & $\cdot / r \mid$ & $\cdot / \cdot \wedge$ & انحر اف معيار & \\
\hline$Y F / 9 D$ & $r \cdot / 10$ & $19 / 10$ & $1 / 9 \Lambda$ & r/VQ & $\cdot / \Delta 9$ & ميانگين & \multirow{2}{*}{ ICU } \\
\hline $10 / 99$ & $1 \% / 99$ & $11 / Y F$ & $9 / 0$ & $r / \cdot F$ & $\cdot / T \Lambda$ & انحر اف معيار & \\
\hline$\varphi \Delta / \cdot \Lambda$ & $r 4 / 9$ & $\mu 1 / \mu$ & $10 / 0$ & $r / \mu$ & $\cdot / f$ & ميانگين & \multirow{2}{*}{ عفونى } \\
\hline FN/DI & FF/YY & $F \cdot / F V$ & $r \cdot / 19$ & $r / F \Delta$ & $\cdot / r r$ & انحر اف معيار & \\
\hline$\cdot / 0$ & $\cdot / 1$ & $\cdot / \cdot 1$ & $\cdot / \cdot r$ &.$/ \cdot 1$ & . & ميانگين & \multirow{2}{*}{ اتاق عمل } \\
\hline.$/ 1 F$ & $1 / \Delta r$ &.$/ .4$ & $.1 \cdot 0$ & .1 .4 & $\cdot$ & انحر اف معيار & \\
\hline$V q / Y$ & $\Delta V / \wedge G$ & Fr/rA & $r \mid / F \Lambda$ & $F / 91$ & .149 & ميانگين & \multirow{2}{*}{ اورخانس } \\
\hline $\mid F / F Y$ & $1 Y / \cdot 9$ & $1 \cdot / T_{F}$ & $F / N$ & $\cdot / 90$ & $\cdot / \cdot \wedge$ & انحر اف معيار & \\
\hline$F F / F G$ & $r 4 / 94$ & $r N / r$ & $10 / 1$ & $f / .1$ & $\cdot / \Delta \Delta$ & ميانگين & \multirow[b]{2}{*}{ هواى بيرون } \\
\hline $9 / 14$ & $r / \pi q$ & $\Gamma / \Lambda \Lambda$ & $1 / \Delta \Delta$ & $\cdot / N r$ & $\cdot / T V$ & انحر اف معيار & \\
\hline
\end{tabular}

مورد مطالعه بود و براى ساير غلظتها، تراكم ذرات در هواى محيط بيرونى نسبت به بعضى از بخشهاى محيط بيشتر و براى تعدادى ديخر كمتر بوده است.

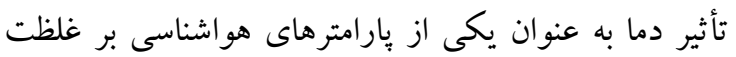

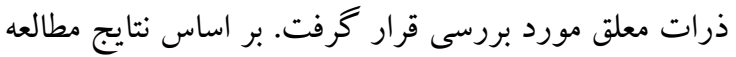

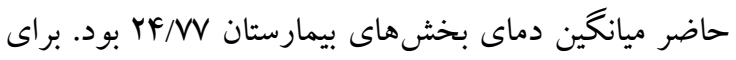
بيشتر بخش هاى بيمارستان در زمستان دماى C C
در اين يزوهش بيشترين و كمترين ميزان آلودگى از نظر غلظت ذرات PM1 به ترتيب مربوط به بخشهاى ICU و اتاق عمل بوده است. در ارتباط با ساير ذرات )

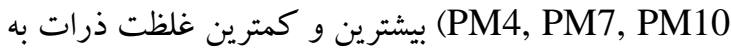
ترتيب در بخشهاى اورزانس و اتاق عمل مشاهده شده است. غلظت ذرات در هواى آزاد براى ذرات كمتر از يك دك

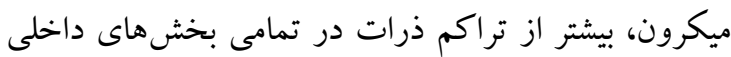


غلظتهاىPM1 و PM2.5 وجود دارد. در بخش مغز و اعصاب در غلظتهاى PM1 و PM4 ارتباط معنىدار مشاهده شد. در بخش اورزانس در غلظتهاى PM4 و ICU ارتباط معنى دار به دست آمده است. در بخش PM10 در همه غلظتها بهجز PM1 رابطه معنىدار مشاهده شد؛ بنابراين مىتوان كفت كه بين رطوبت و غلظت ذرات در قطرهاى مختلف در تمامى بخشها، يك ارتباط مستقيم و معنى دارى مشاهده نشده است. كيفيت هواى بيمارستان از لحاظ وجود ميزان ذرات در قطرهاى $: 1 \cdot \mu \mathrm{m}, \mathrm{v} \mu \mathrm{m}, \mathrm{\Delta} \mu \mathrm{m}$ در اين بررسى با توجه به نتايج سنجش ميزان ذرات در سايزهاى مختلف و به تفكيك بخش هاى مختلف در هواى داخل و خارج بيمارستان توحيد كه در جدول شماره آورده شده است، مشاهده شد كه بيشترين و كمترين ميزان ذرات در قطرهاى

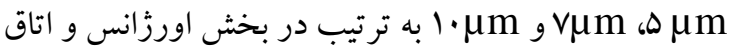
عمل بوده است. همجِنين حداكثر و حداقل ميزان ذرات در

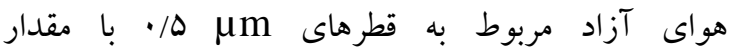
I Im

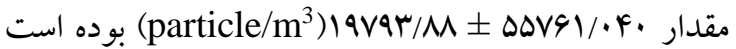

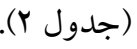

در تابستان C C س تا Y TV توصيه شده است (Y). براى بررسى ارتباط بين دما با غلظت ذرات به تفكيك بخشها، از آزمون ضرايب همبستخى استفاده شد. مطابق آناليزهاى انجام كرفته، در بخشهاى داخلى مردان و زنان، ريه، مغز و اعصاب، اتاق عمل و اورزانس ارتباط معنىدارى بين دما و غلطت ذرات وجود ندارد. بدين معنى كه غلظت ذرات متأثر از دماى محيط نيست. در بخش سوختكى ارتباط معنى دارى بين دما و غلظت ذرات بخش ICU ارتباط معنىدارى بين دما و ذرات معلق در غلظتهاى مختلف بهجز PM1 به دست آمده است. در بخش عفونى در همه غلظتهاى مورد بررسى، دما و غلظت ذرات داراى ارتباط معنىدار و ضريب همبستكى مثبت بود؛ يعنى با افزايش دما در بخش عفونى غلظت ذرات معلق

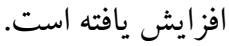
در اين بُزوهش همزمان با نمونهبردارى از ذرات ميزان رطوبت نسبى نيز در محل اندازهگيرى شد. جهت بررسى ارتباط بين RH با غلظت ذرات مشاهده شده در بخشهاى بيمارستان، از آزمون ضرايب همبستكى استفاده شد. نتايج تحليل آمارى نشان داد كه در بخشهاى داخلى زنان، سوختكى، عفونى، اتاق عمل و هواى بيرون ارتباط معنى دارى بين RH و غلظت ذرات وجود ندارد. در بخش ريه ارتباط معنى دارى بين تعداد ذرات مشاهده شده با RH در

جدول r. ذرات اندازهكيرى شده به تفكيك بخشهاى مختلف مورد مطالعه (particle/mº

\begin{tabular}{|c|c|c|c|c|c|c|c|c|c|}
\hline $1 \cdot \mu \mathrm{m}$ & $\vee \mu \mathrm{m}$ & $\Delta \mu \mathrm{m}$ & $\varphi \mu \mathrm{m}$ & $r / \Delta \mu \mathrm{m}$ & $1 \mu \mathrm{m}$ & $\cdot / \nabla \mu \mathrm{m}$ & $\cdot / \Delta \mu \mathrm{m}$ & انحر اف ميانكين و & مختى \\
\hline $1 F 9 \Delta N / F r$ & rATYV/FF & $9 \Delta Q \Delta F / .9$ & IroV^Q/19 & MFAYVD/GY & $V \cdot r 4 \Lambda \cdot / \Lambda \cdot$ & $94.94 \cdot 119$ & $19 V V I T V / A 1$ & انحر اف معيار & داخلى \\
\hline$|A Y| \cdot / r \Delta F$ & MFINI/AGV & VGYAN/G. I & $|F| \Lambda \mid V / 9 \cdot 1$ & MVIMN/.1. & VYFMTD/YDS & QRTVIN/AVA & IDFQVFFF/FDG & انحر اف معيار & مردان \\
\hline$\Delta \wedge Y F / \Delta$. & $111 \mathrm{Fr} / \Delta \mathrm{r}$ & roIrq/OV & FVDVQ/DI & $1 F \wedge 999 / \cdot r$ & rAYGVQ/GT & DAYFFT/YA & IYSFIYY/D. & ميانگين & داخلى \\
\hline GYIQ/VNI & $\| \Delta F I / A M V$ & $r \Delta F \cdot \Delta /|9|$ & FVVYN/GVG & Irarrr/agr & rG. IAV/rDI & $\triangle D G M A / Y Y G$ & $1.99991 / \% 1 V$ & انحر اف معيار & 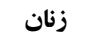 \\
\hline AVIG/IF & 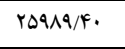 & $F F \cdot$ FY/MA & IIGFFA/VV & YVFIVD/D. & $\Delta F A V \Delta V / T G$ & AMTVGT/YD & rFq৭Ard/l. & ميانگين & \\
\hline $9.09 / 491$ & TVYAN/FAD & FNH.N/9N. & $114.99 / .41$ & TVGNYA/YVD & $\Delta 9 \Delta M M Y / 9 \Delta Q$ & 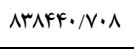 & Yr. YMTV/AII & انحراف معيار & \\
\hline$V \Delta Q / V Y$ & $11199 / 94$ & $r \Lambda \cdot r / r$. & $\Delta V F Y / \cdot \Delta$ & loVDr/Ar & HG. FN/Yq & $\Delta F \Delta Q 9 / \Delta r$ & IrGAVN/GN & ميانگين & مغز و \\
\hline$r \mid f / .90$ & $r V / \cdot r r$ & $\Delta \Delta \cdot / Q \cdot \Delta$ & $\mid F V F / 9 \cdot \Delta$ & $\mathrm{rAIV} / .9 \mathrm{~V}$ & VMAQ/199 & IFFFI/990 & $4 \cdot \wedge 9 \wedge / r q 9$ & انحر اف معيار & اعصاب \\
\hline YIV/q. & $\Delta \Delta r / \Delta q$ & $11 \wedge r / v \Delta$ & rolF/VT & $1 . F A Y / A Y$ & $r \cdot \Delta Y F / \Delta$. & GYVGV/AG & rmYArN/vo & ميانگين & \\
\hline $91 / F \vee q$ & rTS/rTA & r.V/AYF & rVG/AqV & YIFI/VAI & 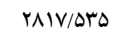 & $\Lambda F F \cdot / \Lambda q$. & $F q \Delta Q F / \Delta Y Q$ & انحر اف معيار & \\
\hline rDGN/q. & $9499 / \mathrm{V}$ & TI. $49 / 01$ & $V \notin q V \cdot / \Delta \Delta$ & 1.90/99 & $1.1 F V A V / q 9$ & $1919499 / 44$ & req1999//r & ميانگين & ICU \\
\hline
\end{tabular}


IV افشين هلكى

\begin{tabular}{|c|c|c|c|c|c|c|c|c|c|}
\hline $1 \cdot \mu \mathrm{m}$ & $\vee \mu \mathrm{m}$ & $\Delta \mu \mathrm{m}$ & $\varphi \mu \mathrm{m}$ & $r / \Delta \mu \mathrm{m}$ & $\mathrm{I} \mu \mathrm{m}$ & $\cdot / \vee \mu m$ & $\cdot / \Delta \mu \mathrm{m}$ & انحرانكين و & مخش- مختى \\
\hline$r \Delta \wedge \varepsilon / \cdot q r$ & $9 F \mid 9 / \cdots D$ & $M Y . F F / V A$. & WVGY/AM. & MFNIQG/FYY & l.VDIYIVYA & $|V| \cdot \Delta V \cdot / Y r Y$ & ralgFDN/IV. & انحر اف معيار & \\
\hline$V \wedge 91 / 94$ & IDARG/YA & rqYqT/rq & VATVD/VF & ro1A91/.1 & $\Delta A Y G / F / A F$ & $\Lambda F \Delta G \Delta R / V I$ & $19.9 \Delta \Lambda F / r Y$ & ميانكين & \multirow{2}{*}{ عفونى } \\
\hline QMMY/QFA & $191 \mid F / Y 1$. & FAVYQ/AVD & $9 M M 1 / Y \cdot 1$ & rIVGTD/.FV & $V F F V \wedge q / \cdot 19$ & $1 \cdot q \cdot 0 \cdot 4 / r v q$ & rDFDGND/VVD & انحر اف معيار & \\
\hline$r \Delta / r F$ & $I V / 9 V$ & $V \cdot 19 \mathrm{~V}$ & $111 / 9$. & $r \cdot 9 / r F$ & $|F r| /$. & rrVQ/1D & $9 \times 9 . / D F$ & ميانگين & \multirow{2}{*}{ اتاق عمل } \\
\hline YY/MYA & $19 / r \Delta V$ & Tr/MFA & $\Delta r / \cdot 11$ & re/kqf & $r q . / 1 r q$ & $\Delta F G / T Q T$ & 1. & انحر اف معيار & \\
\hline$r v r q u / \cdot 0$ & GFAVG/MT & $10 . F F 1 / V$ & rgFVQ৭/VV & $1.94 .91 / 41$ & $|\Lambda F| \Delta r \Delta / \mu r$ & VQTFFESN/IQ & YVIFAYY/QV & ميانگين & \multirow{2}{*}{ اورزانس } \\
\hline FOYI/AMA & IGVAI/TVG & YMMN/VGQ & IrHGFY/IYq & $\Delta \Delta \cdot V Y V / F \cdot Q$ & llMorl/rar & $\mid r \cdot V I V \cdot F / g r V$ & rrYG191/r.9 & انحر اف معيار & \\
\hline I9V9r/MA & FDIMA/FG & $110 V r 4 / 19$ & rrIarI/91 & $V \cdot V \wedge G \Lambda / \cdot \wedge$ & IOGVFYG/TN & $r \cdot V \Delta r M / 9 q$ & $r G q \cdot \lambda F r / l V$ & ميانگين & هواى \\
\hline
\end{tabular}

اورزانس در اندازههاى دارى بين تعداد ذرات و دما مشاهده شد و در بقيه موارد

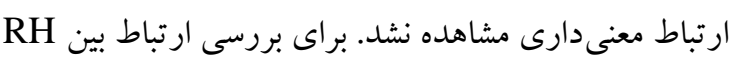

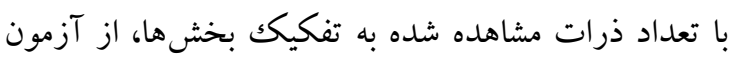

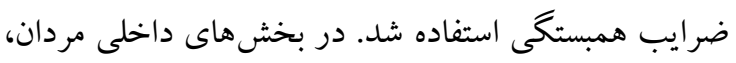
مغز و اعصاب، عفونى و هواى بيرون ارتباط معنىدارى بين RH ارتباط معنىدارى بين تعداد ذرات مشاهده شده با RH در لعرداه

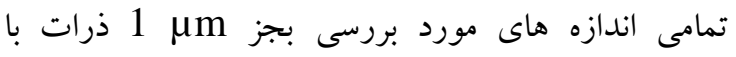

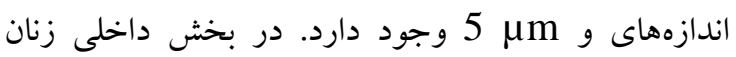

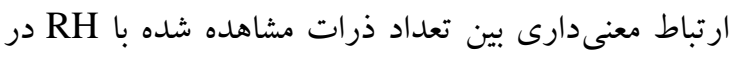

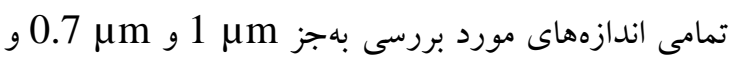
0.5 Mm دارى بين تعداد ذرات مشاهده شده با RH وجود ندارد فقط در اندازههاى 7 و 7 m 5 ارتباط معنىدارى بين تعداد ذرات و RH در بخش سوختكى وجود دارد. در بخش ارتباط معنى دارى بين تعداد ذرات مشاهده شده با دما ICU در تمامى اندازههاى مورد بررسى وجود دارد. در بخش اتاق عمل فقط در اندازه 1 m ارتباط معنىدارى بين RH و تعداد ذرات مشاهده شد. در بخش اورزانس در اندازههاى

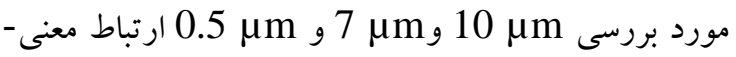
دارى بين RH و تعداد ذرات مشاهده است. در اين بررسى با توجه به نتايج سنجش ميزان ذرات در سايزهاى مختلف و به به دراس
با استفاده از آزمون آناليز واريانس يككطرفه ارتباط بين ذرات و بخش هاى مختلف مورد بررسى قرار گرفت. نتايج

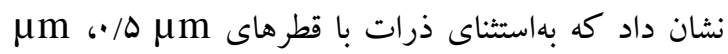

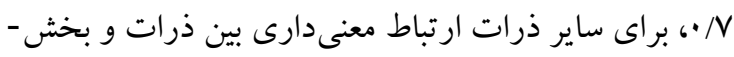
هاى مختلف مشاهده شد. به اين معنى كه تعداد ذرات

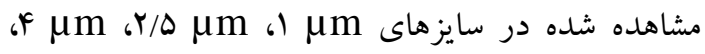

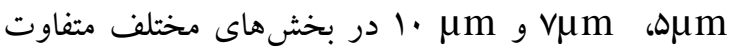

براى بررسى ارتباط بين دما با ذرات مشاهده شده به تفكيك

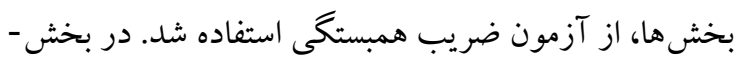

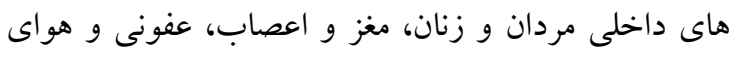
بيرون ارتباط معنىدارى بين دما و تعداد ذرات مشاهده شده وجود ندارد. در بخش ريه ارتباط معنىدارى بين تعداد ذرات مشاهده شده با دما در تمامى اندازه هاى مورد بررسى وجود دارد. در بخش سوختكى در همه اندازههاى مورد بررسى ارتباط معنىدارى بين دما و تعداد ذرات مشاهده

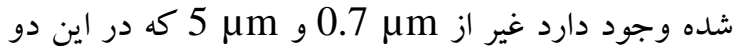
اندازه مورد بررسى بين تعداد ذرات و دما ارتباط معنىدار مشاهده نشد. در بخش ICU ارتباط معنىدارى بين تعداد ذرات و دما در تمامى اندازه هاى مورد بررسى وجود دارد. در بخش اتاق عمل فقط در مورد ذرات با اندازه هاى 2.5 ارتباط معنى دارى بين تعداد ذرات و دما مشاهده شد و در بقيه موارد ارتباط معنىدارى وجود ندارد و در بخش 
تفكيك بخش هاى مختلف در هواى داخل و خارج آوختلف در جدول شده است. بيمارستان، بيشترين و كمترين ميزان ذرات در قطرهاى

جدول س. بالاترين و هايين ترين مقدار ذرات در بخش هاى بيمارستان (particle/m³

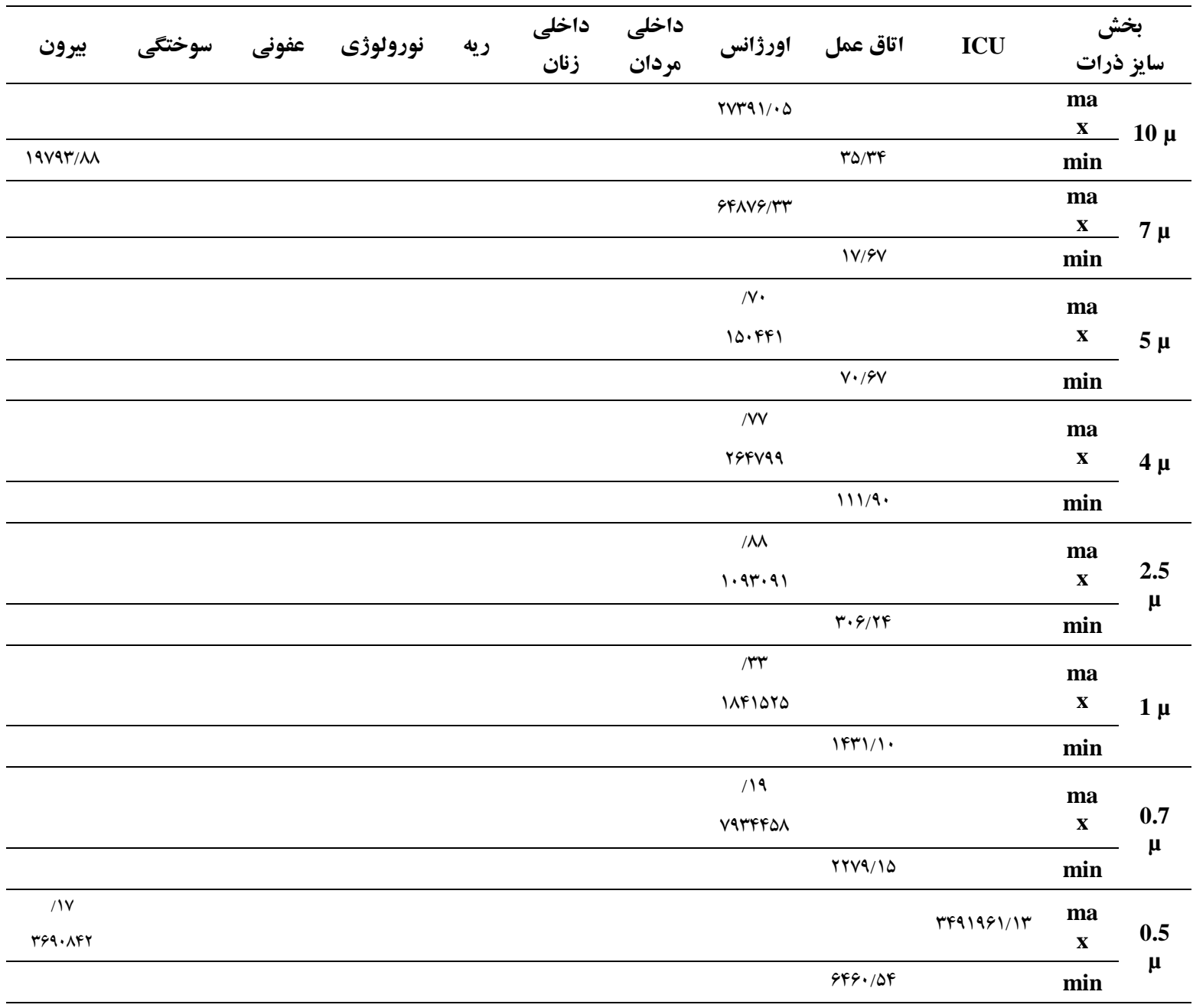

زنان، داخلى مردان، نورولوزى، مغز و اعصاب و اتاق عمل مدلسازى يراكندكى آلاينده ها با استفاده از نرم افزار بوده است. نقشههاى تهيه شده بر اساس دادههاى حاصل از :SURFER

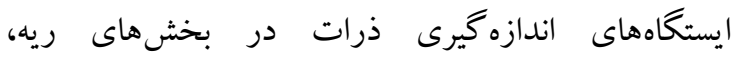
با توجه به اهميت بهداشتى ذرات PM2.5 نسبت به ساير نورولوزى، عفونى و هواى آزاد نشان داد كه ميزان انتشار و ذرات، نقشه هاى مربوط به توزيع ميزان ذرات با استفاده از غلظت آلايندهها در قسمتهاى شرقى داراى براكندگى نرم افزار Surfer تنها براى ذرات PM2.5 تهيه شد و مورد بالاتر بوده است و هرجّه به سمت قسمتهاى غربى نقشه تجزيه و تحليل قرار گرفت. نرم افزار سارفر توزيع احتمالى بيش مى روود ميزان انتشار و كانترهاى براكندگى كمتر مى آلاينده در قسمت مورد نظر را براى ما ترسيم مى كند. با

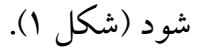
توجه به نقشه هاى حاصل از كليه بخشها، بالاترين ميزان آلاينده احتمالى در بخش عفونى و به دنبال آن به ترتيب در هواى بيرون بيمارستان، بخش اورزانس، ICU، ريه، داخلى 


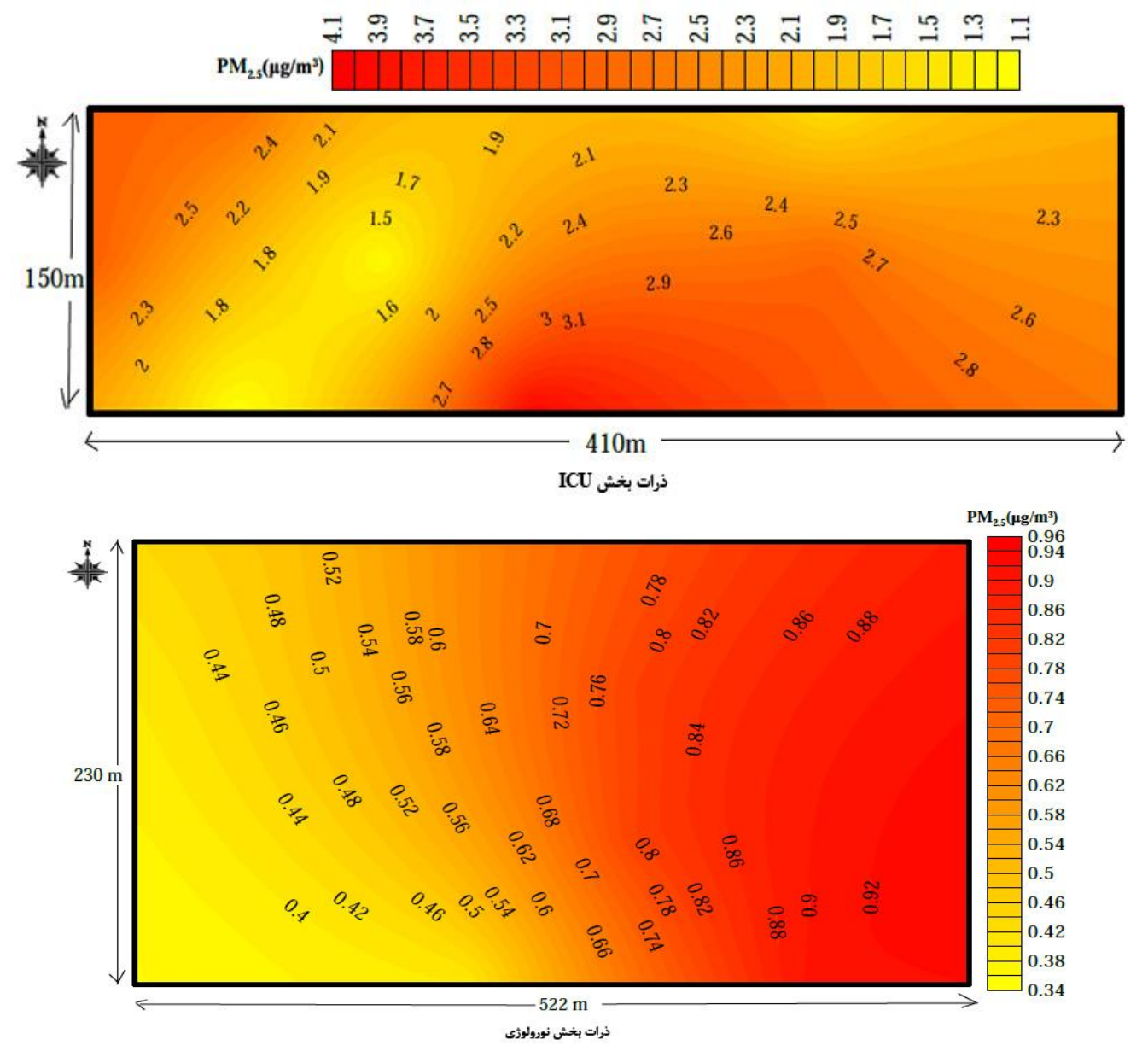

شكل ا. يراكندكى آلاينده PM2.5 با استفاده از نرم افزار SURFER براى دو بخش ICU و نورولوزى

بر اساس سنجش غلظت ذرات در هواى آزاد توالى ( ( $\mathrm{PM}_{2.5}<\mathrm{PM}_{4}<\mathrm{PM}_{7}<\mathrm{PM}_{10}$ غلطت ذرات در بخشهاى مختلف بيمارستان تحت تأثير فاكتورهايى از قبيل تعداد تختهاى هر اتاق، تعداد بيماران

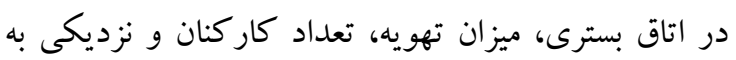

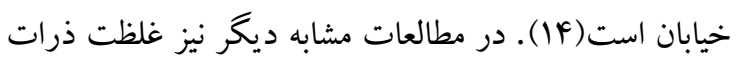
در بخشهاى بيمارستانى مورد بررسى قرار گرفتهاند. در

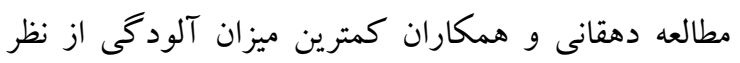

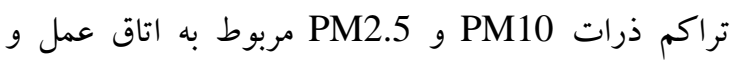
بخش زايمان بوده است كه با نتايج بررسى هاى اين مطالعه

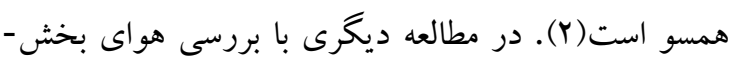
هاى بيمارستان شهيد بهشتى حداقل و حداكثر ميانخين
بيشترين عدد منحنىهاى كانتر در قسمت شرقى بخش

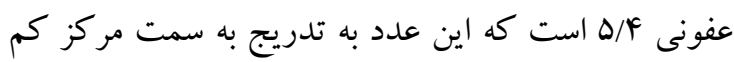
مىشود و در كنارههاى غربى به عدد

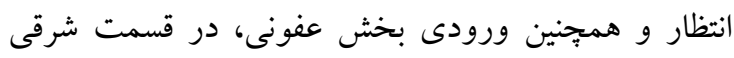

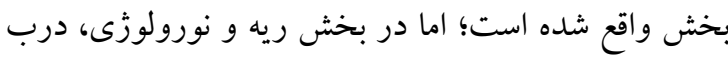
ورودى در غرب نقشه واقع شده است. در ساير بخشها

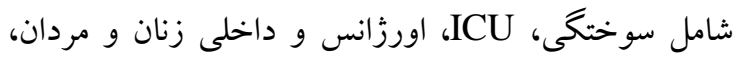

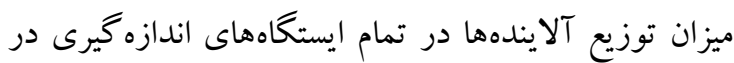

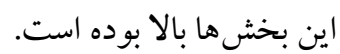
بحث 
داخل بيمارستان به بخشهاى اطفال و اتاق عمل اختصاص

غلظت ذرات PM2.5 به بخش ICU و بخش اطفال و

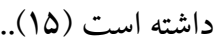

حداقل و حداكثر ميانخين غلطت ذرات PM10 در هواى بحت

جدول †. استاندارد EPA جهت كيفيت هواى محيط براى آلايندههاى PM2.5 و PM10 (19)

\begin{tabular}{|c|c|c|c|c|c|}
\hline به شكل & ميزان & متوسط زمان & اوليه /ثانويه & & آلايند \\
\hline ميانخين سالانه، به طور متوسط بيش از ب سال & $1 \mathrm{r} \mu \mathrm{g} / \mathrm{m}^{3}$ & اسل & اوليه & \multirow{3}{*}{ PM2.5 } & \multirow{4}{*}{ ذآلودىى } \\
\hline ميانخين سالانه، به طور متوسط بيش از ب سال & $1 ه \mu \mathrm{g} / \mathrm{m}^{3}$ & ا سال & ثانويه & & \\
\hline 19/، به طور متوسط بيش از ب سال & $r \Delta \mu \mathrm{g} / \mathrm{m}^{3}$ & 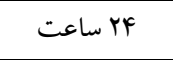 & اوليه و ثانويه & & \\
\hline بيش از يكك بار در سال به طور متوسط بيش از & $10 \cdot \mu \mathrm{g} / \mathrm{m}^{3}$ & ساعت YF & اوليه و ثانويه & PM10 & \\
\hline
\end{tabular}

دست آمده است كه اين افزايش غلظت ذرات در بخشهاى و و عفونى، مىتواند به دلايلى از جمله تعداد زياد بيماران بسترى در بخش، تردد زياد همراهان و همجِين حضور دانشجويان كارآموز در اين بخشها، استفاده از وسايل شخصى غير استريل و توسط همراهان و بيماران،

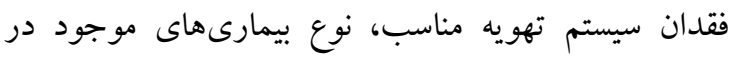
بيماران بخش، كهنه و فرسوده بودن بخش باشد (1) (1)؛

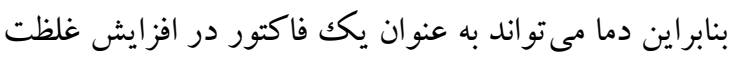
ذرات در نظر گرفته شود. شكرى و همكاران نيز در مطالعه -

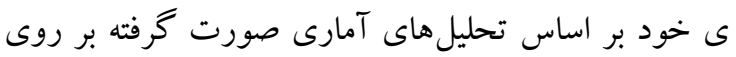

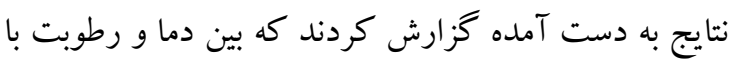

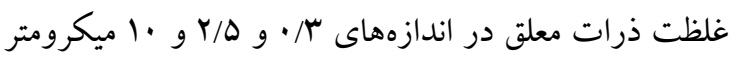
در هواى محيط داخل بين بخشها ارتباط مثبت معنىدارى

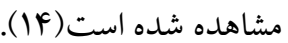
در اين مطالعه بين رطوبت و غلظت ذرات در قطرهاى مختلف در تمامى بخشها، يك ارتباط مستقيم و معنى دارى مشاهده نشده است. بر اساس اطلاعات به دست آمده از

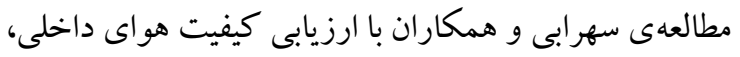

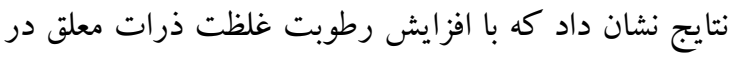
محيط داخلى افزايش يافته است درحالى كه اين نتايج براى محل هاى با سطح بالاى غلظت ذرات صادق نبوده است (1). همجنين در مطالعه اتابكى و همكاران كه در هواى آزاد شهر

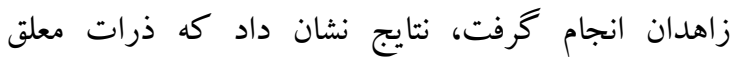

دهقانى و همكاران غلظت ذرات معلق PM10 و 2.5 PM در هواى برخى از بخشهاى داخل و هواى اطراف

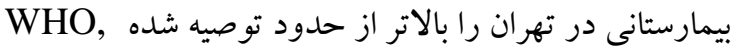
كزارش نمودند و كيفيت هواى داخل را متأثر از USEPA هواى محيطى عنوان نمودند (r) (1). نتايج مطالعات مشابهى نيز نشان داده است كه بين غلظت ذرات در هواى بخشهاى هرئ مختلف بيمارستان با همديخر و نيز با هواى بيرون ارتباط

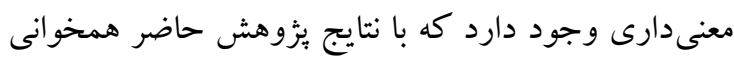
دارند. در اين مطالعه هم غلظت ذرات در هواى بيرون كمتر

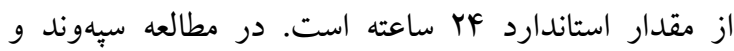

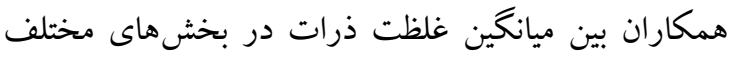
تفاوت معنى

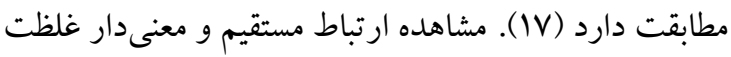
ذرات بين بخشهاى داخل بيمارستان و محيط بيرون مى-

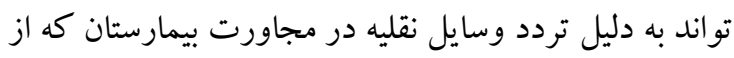
منابع مهم انتشار ذرات به شمار مىروند، بالا بودن ميزان تردد و تراكم افراد در محوطه بيمارستان، ورود آلايندههاى

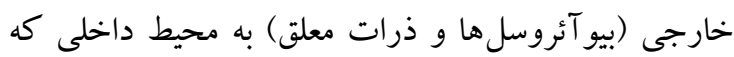

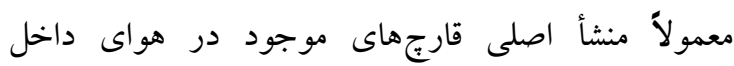
بيمارستان مىباشند و همجنين جابجايى نامناسب هوا در بخش هاى داخلى باشند (1). همانطور كه گفته شد، در بخش ICU و عفونى ارتباط معنىدارى بين دما و ذرات معلق در غلظتهاى مختلف به 
از مقدار استاندارد YF ساعته WHO , USEPA است

(19) (جدول شماره F) (19)

يافتهاى حاصل از يُزوهش حاضر نشان داد كه تقريباً در بيشتر نمونها بهجز بخش اورزانس، نسبت آلايندهاى

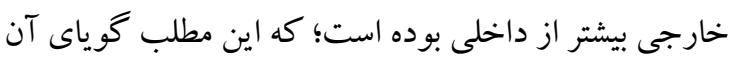

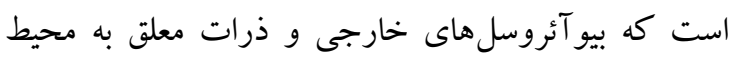

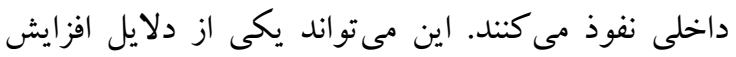
آلايندهاى هوابرد محيط داخلى بيمارستان از طريق مجارى سيستم تهويه نامناسب باشد. با توجه به دادههاى

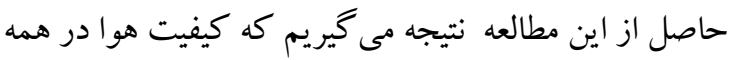
بخشهاى بيمارستان از وضعيت مناسبى برخوردار است و اين مىتواند دلايلى مانند فصل نمونهبردارى، استفاده از تجهيزات مناسب كنترل كننده آلايندها و طراحى مناسب ساختمان و همجنين بستن دريجههاى نفوذ هوا به محيط

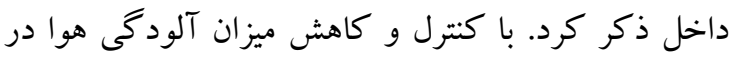
بخشها، مىتوان بسيارى از بيمارىها و عفونتهاى بيمارستانى را كاهش داد. در نهايت ييشنهاد مى شود كه علاوه بر بالا بردن عملكرد اگزوفنها با تعويض به موقع فيلترها جهت تخليه هواى موجود در بخشها، از هواساز جهت ورود هواى تازه به بخش استفاده شده و حتى الامكان از باز كردن ينجرهها اجتناب شود.

\section{تقدير و تشكر}

اين مقاله مستخرج از بايان نامه كارشناسى ارشد مصوب مر كز تحقيقات بهداشت محيط كردستان است كه با حمايت مالى دانشگاه علوم يزشكى كردستان انجام شده است (IR.MUK.REC.1397/226)؛ لذا نويسندكان اين مقاله از حاميان مالى طرح و همكاران اجرايى تشكر مىنمايند. مسئوليت صحت كليه نتايج و مطالب به عهله دانشجو است.
با بارامتر رطوبت همبستخى معكوس دارد و رابطه معنى دارى با همديخر نداشتند(r). مطابق دادههاى حاصل از جدول ب، آلودهترين بخش از نظر حضور ميزان ذرات مربوط به بخش اورزانس بود كه به

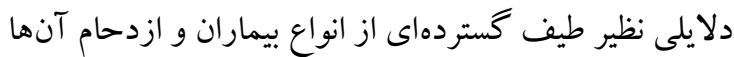
در اورزانس نسبت به ساير بخشها يا تردد بالاى

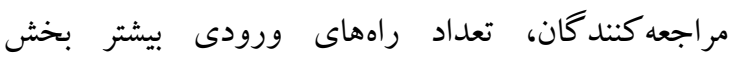
اورزانس، عدم رعايت موازين بهداشتى، استعمال دخانيات و تهويه ناكافى مى توان اشاره نمود (19, ·Y). همجنين در اين مطالعه بهترين شرايط براى بخش اتاق عمل مشاهده شد كه

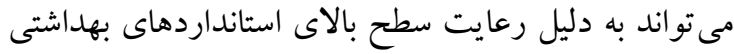
مانند محدود بودن تردد افراد، تعداد كمتر بيماران، بسته بودن در ورودى بخش و تهويه مناسب و استريليزاسيون و

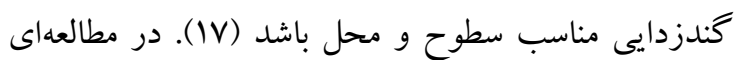
كه توسط نيككيى و همكاران انجام گرفت، بيشترين تعداد ذرات با قطرهاى r/· و ه/ه ميكرومتر به بخش اورزانس اختصاص داشته است(f()). در مطالعه شكرى و همكاران بالاترين تعداد ذرات معلق در قطرهاى كمتر از •ا و هاه ميكرومتر مربوط به بخش قلب مردان و حداقل تعداد ذرات

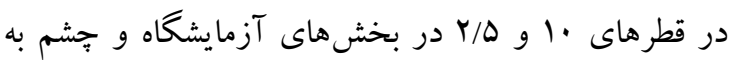

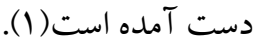
طبق نتايج به دست آمده توسط نرم افزار سارفر، قسمت ورودى بخش عفونى (سمت شرق بخش) داراى بالاترين ميزان تراكم ذرات بوده كه از عمده دلايل آن مىتواند قرار گرفتن اتاق انتظار در ورودى بخش و تردد بالا در اين قسمت ها باشد. اين در حالى است كه ميزان توزيع آلايندهها در ساير بخشها از توزيع يكنواختى برخوردار بود.

\section{نتيجه كيرى}

نتايج حاصل از اين مطالعه نشان داد كه ميانخين غلطت ذرات در تمامى بخشهاى بيمارستان و نيز هواى آزاد، كمتر 


\section{Reference}

1.Rezaei S, Naddafi K, Jabbari H, Yonesian M, Jamshidi A, Sadat A, et al. Relationship between the particulate matter concentrations in the indoor and ambient air of the Tehran children hospital in 2007. Iran J Health Environ. 2013;6(1):103-12.

2.Sepahvand A, Godini H, Omidi Y, Tarrahi M, Rashidi R, Basiri H. Investigation of fungal bioaerosols and particulate matter in the teaching-medical hospitals of Khorramabad City, Iran during 2015. Iran J Health Environ. 2016;9(1):115-26.

3.Ibrahim A. A System for Monitoring and Managing Indoor Air Quality and Environmental Conditions. 2016.

4.Dehghani M, Kamali Y, Ghanbarian M, Shamsedini N. Study of the Relationship between Indoor. Outdoor Particle.

5.Tiwary A, Williams I. Air pollution: measurement, modelling and mitigation: CRC Press; 2018.

6.Chinn RY, Sehulster L. Guidelines for environmental infection control in health-care facilities; recommendations of CDC and Healthcare Infection Control Practices Advisory Committee (HICPAC). 2003.

7.Pirdosti PS, Sahraei DJ. Assessment of Indoor Air Quality of Residential Homes in Kermanshah. Environ Sci Studies. 2019;1(4):1012-02.

8.Bell ML, Ebisu K, Peng RD, Samet JM, Dominici F. Hospital admissions and chemical composition of fine particle air pollution. American $\mathrm{J}$ Res Critic Care Med. 2009;179(12):1115-20.

9.Janssen NA, Schwartz J, Zanobetti A, Suh HH. Air conditioning and source-specific particles as modifiers of the effect of PM (10) on hospital admissions for heart and lung disease. Environ Health Persp. 2002;110(1):43-9.

10.Wang X, Bi X, Sheng G, Fu J. Hospital indoor PM10/PM2. 5 and associated trace elements in Guangzhou, China. Sci Total Environ. 2006;366(1):124-35.

11.Menetrez M, Foarde K, Esch R, Dean T, Betancourt D, Moore S, et al. The measurement of ambient bioaerosol exposure. Aerosol Sci Tech. 2007;41(9):884-93.

12.Wassouf M BI. Analysis of Total SuspendedParticles (TSP) and Total Organic Carbon (TOC) in

Air Samples. School of Public and Environmental

Affairs1995.

13.DEHGHANI M, SAEEDI AA, ZAMANIAN Z. A study of the relationship between indoor and outdoor particle concentrations in Hafez Hospital in Shiraz, Iran. 2012.

14.Massoudinejad M, Ghajari A, Hezarkhani N, Aliyari A. Survey of Environmental Bioaerosols in ICU ward of Taleghani Hospital in Tehran by Petri-dish trapping technique and Bioaerosol Sampler in 2013. J Safe Promotion Injury Prevention. 2014;2(2):133-9.

15.Shokri S, Nikpey A, Varyani AS. Evaluation of hospital wards indoor air quality: the particles concentration. Journal of Air Pollution and Health. 2016;1(3):205-14.

16.Maroni M, Seifert B, Lindvall T. Indoor air quality: a comprehensive reference book: Elsevier; 1995.

17.Mohammadyan M, Keyvani S, Yazdani-Charati J, Bahrami A, Yousefi-Nejad R. Indoor and ambient air concentrations of respirable particles between two hospitals in Kashan (20142015). KAUMS Journal (FEYZ). 2017;21(1):66-73.

18.Huang P-Y, Shi Z-Y, Chen C-H, Den W, Huang H-M, Tsai J-J. Airborne and surfacebound microbial contamination in two intensive care units of a medical center in central Taiwan. Aerosol Air Qual Res. 2012;13(3):1060-9. 
19.El-Sharkawy MF, Noweir ME. Indoor air quality levels in a University Hospital in the Eastern Province of Saudi Arab. J Fam Com Med. 2014;21(1):39.

20.Bhatia L, Vishwakarma R. Hospital indoor airborne microflora in private and governmentowned hospitals in Sagar City, India. World J Med Sci. 2010;5(3):65-70. 